\title{
Human Papillomavirus-56
}

National Cancer Institute

\section{Source}

National Cancer Institute. Human Papillomavirus-56. NCI Thesaurus. Code C103003.

A virus comprised of a protein coat (capsid) surrounding a circular, double-stranded DNA organized into coding and non-coding regions, which can induce epithelial lesions.

Infection with human papillomavirus-56 is associated with a high risk for cervical intraepithelial neoplasia. 